\section{A new illusion: The underestimation of distance during pursuit eye movements}

\author{
ARIEN MACK and EDWARD HERMAN \\ New School for Social Research, New York, N.Y. 10011
}

A new visual illusion is reported. The apparent distance through which a displaced target appears to move is significantly shorter when pursuit tracked than when that same distance is observed by means of a saccadic eye movement. This misperception of distance seems to be related to the Aubert-Fleischl paradox, the underestimation of the velocity of a tracked target, and to reveal a consistent characteristic of the pursuit eye movement system.

Pursuit eye movements are known to give rise to various modes of nonveridical perception. For example, stationary background objects lying behind the path of a moving and tracked target appear to move (Filhene, 1922; Mack \& Herman, in press). Also, a moving target pursued by the eyes appears to move more slowly than if observed by a stationary eye, a phenomenon that has been labeled the Aubert-Fleischl paradox (Fleischl, 1882). The experiments reported here provide evidence of yet another kind of misperception associated with the pursuit of a moving target. The results of the initial experiments reported below reveal a consistent underestimation of the distance through which a tracked target has moved. In these experiments, Ss' estimates of linear distance were obtained following the observation of a single luminous disk as it moved through a set distance in an otherwise dark field and was tracked by the eyes (tracking condition). These estimates were compared with estimates of distance following fixation of two successively and briefly illuminated points of light separated by the same distance as the distance through which the tracked target had moved (saccadic condition). The rationale for using distance estimates from saccadic observation as the baseline against which to ascess tracking estimates was that (1) it seemed reasonable to compare distance estimates following one type of eye movement with distance estimates following a different sort of eye movement, and (2) it has been reported (Festinger \& Canon, 1965) that saccadic movements lead to a quite accurate perception of target location, an aspect of perception closely related to the perception of frontal-parallel distance.

\section{EXPERIMENT I} Apparatus

The tracking target was a $1.5-\mathrm{mm}$ luminous disk mechanically driven through an angle of $20 \mathrm{deg}(11.4 \mathrm{~cm})$ over a nylon track located $30 \mathrm{~cm}$ from the $\mathrm{S}$ in his frontal-parallel plane. The target moved from left to right beginning from a position $10 \mathrm{deg}$ to the left of the S's median plane at a constant rate of either $4.5 \mathrm{deg} / \mathrm{sec}$ or $10.5 \mathrm{deg} / \mathrm{sec}$, and it disappeared from view behind an opaque mask when it reached a position $10 \mathrm{deg}$ to the right of the S's median plane.

The sitmuli used for the saccadic observation condition consisted of two successively lit disks of light (1.5-mm diam), equated for brightness with the moving target. The light initially illuminated was located in the S's median plane, while the other light was placed 20 deg to its right. 1 Both lights were at a distance of $30 \mathrm{~cm}$ from the S's frontal-parallel plane.

The apparatus for obtaining distance estimates was also located in the S's frontal-parallel plane at a distance of $30 \mathrm{~cm}$ and consisted of a slide rule-like device to which were affixed two $1.5-\mathrm{mm}$ luminous points. One of the points was immobile, while the other could be moved towards or away from the fixed point.

\section{Procedure} estimate of distance following each of the 12 trials of target tracking and following each of the 12 trials of saccadic observation. The first two estimates in each observation condition were considered practice and were not included in calculation of the data. The order of observation conditions was counterbalanced, as was the sequence of ascending and descending judgment trials.

At the beginning of a tracking trial, the $S$ fixated the luminous target disk and was instructed to track it as accurately as possible when it moved and until it disappeared from view. At the start of a saccadic observation trial, the $\mathbf{S}$ was instructed to fixate the initially illuminated target light and to turn his eyes to the second light as soon as it appeared. The time interval between the onset of the initial fixation light and the onset of the
Ss were required to make an second light was equal to the time required for the moving target to travel $20 \mathrm{deg}$ at either $4.5 \mathrm{deg} / \mathrm{sec}$ or $10.5 \mathrm{deg} / \mathrm{sec}$. Thus, the initial fixation light remained on for either 1.5 or $4 \mathrm{sec}$ and was coordinated with the appearance of the second light, which remained on for .5 sec. Immediately following each observation trial, the $S$ was asked to report when the distance between the two simultaneously presented luminous points on the slide rule device matched either the distance through which the tracked target had moved or the distance between the two successively fixated target lights. The $\mathbf{E}$ gradually increased or decreased the distance between these points until the $\mathbf{S}$ indicated that a distance match had been achieved.

The S's head was fixed in position by a chinrest throughout the experiment. All testing was done in a completely darkened room, and the $S$ wore earphones through which he heard taped white noise which blocked out motor noises.

\section{Subjects}

Twelve Ss were tested, all of whom were students at one of various surrounding universities and all of whom were paid for participation. Six Ss tracked the target at $4.5 \mathrm{deg} / \mathrm{sec}$ and were tested with a saccadic observation interval of $4.4 \mathrm{sec}$. The remaining six Ss tracked the target at a speed of $10.5 \mathrm{deg} / \mathrm{sec}$ and were tested with a saccadic observation interval of 1.9 sec.

\section{Results}

Lines 1 and 2 of Table 1 report these results. The mean differences between saccadic and tracking distance estimates are significant and thus reveal a clear underestimation of tracking distance. ${ }^{2}$

\section{EXPERIMENT II}

In order to demonstrate that the obtained differences between tracking and saccadic observation were, in fact, a function of the different types of eye movements and were not simply a function of the fact that in one condition the distance is demarked by a moving target while in the other it is demarked by successively appearing lights, 12 new Ss were tested, making distance estimates following (1) observation of the moving target while fixating a small fixed luminous point located in the center of the target track and (2) observation of the successively appearing lights while fixating another luminous point located mid-way between the two lights. The moving target traveled at $4.5 \mathrm{deg} / \mathrm{sec}$. The apparatus was simply modified by introducing two small fixation points into the field; one in 
Table 1

Mean Distance Estimates

\begin{tabular}{|c|c|c|c|c|c|c|c|c|c|}
\hline \multirow{4}{*}{\multicolumn{2}{|c|}{$\begin{array}{l}\text { Experi- } \\
\text { ment }\end{array}$}} & \multirow{4}{*}{$\begin{array}{c}1 \\
\text { Target } \\
\text { Speed } \\
\text { (Deg/Sec) }\end{array}$} & \multirow{4}{*}{$\begin{array}{c}2 \\
\text { Distance } \\
\text { (Actual) } \\
\text { (Cm) }\end{array}$} & \multicolumn{4}{|c|}{$\begin{array}{cc}3 & 4 \\
\text { Mode of } & \text { Observation } \\
\end{array}$} & \multirow{3}{*}{\multicolumn{2}{|c|}{ Difference }} \\
\hline & & & & \multicolumn{2}{|c|}{ Saccadic } & \multicolumn{2}{|c|}{ Tracking } & & \\
\hline & & & & Mean & & Menn & & & \\
\hline & & & & (Cm) & Ratio & (Cm) & Ratio & $\mathrm{Cm}$ & Deg \\
\hline I & $\begin{array}{l}\mathbf{1} \\
\mathbf{2}\end{array}$ & $\begin{array}{r}4.5 \\
10.5\end{array}$ & $\begin{array}{l}11.4 \\
11.4\end{array}$ & $\begin{array}{l}11.99 \\
12.01\end{array}$ & $\begin{array}{l}(1.04) \\
(1.05)\end{array}$ & $\begin{array}{r}9.66 \\
10.77\end{array}$ & $\begin{array}{l}(.83) \\
(.94)\end{array}$ & $\begin{array}{l}2.33 * * \\
1.24 * *\end{array}$ & $\begin{array}{l}4.4 \\
2.3\end{array}$ \\
\hline II & 3 & 4.5 & 11.4 & $11.08 *$ & $(.97)$ & $11.19 *$ & $(.98)$ & .11 & .21 \\
\hline IV & 4 & 10.5 & 26.6 & 25.4 & $(.95)$ & 22.5 & $(.84)$ & $2.89 * *$ & 5.5 \\
\hline
\end{tabular}

\begin{tabular}{cccccc}
\hline $\begin{array}{c}\text { Experi- } \\
\text { ment }\end{array}$ & $\begin{array}{c}\text { Target } \\
\text { Speed } \\
\text { (Deg/Sec) }\end{array}$ & $\begin{array}{c}\text { Vean } \\
\text { Tracking } \\
\text { (Deg/Sec) }\end{array}$ & $\begin{array}{c}\text { Mode of Observation } \\
\text { Fixation } \\
\text { (Deg/Sec) }\end{array}$ & $\begin{array}{c}\text { Difference } \\
\text { (Deg/Sec) }\end{array}$ \\
\hline \multirow{2}{*}{ III } & 5 & 6.5 & 3.87 & 4.82 & .96 \\
& 6 & 10.5 & 7.99 & 9.13 & 1.14 \\
\hline
\end{tabular}

*Control condition: $S s$ fixated a stationary point while observing the moving target. and the successively appearing target lights.

**Significant at or below .05

Note-1 deg $=.52 \mathrm{~cm}$

the center of the target track and one mid-way between the saccadic lights. The procedure was identical to that of Experiment I except for the differences already noted.

\section{Results}

Line 3 of Table 1 reports this data. The mean difference between the two modes of observation was $.11 \mathrm{~cm}$ and is, of course, not significant. This result allows us to conclude that the reported differences between the tracking and saccadic conditions are in fact a function of the different modes of observation and not of the different ways in which the distance was defined. Taken together, these results clearly demonstrate an underestimation of distance during tracking, relative to estimation of distance based on saccadic observation. It should also be noted that the estimations of tracking distance also represent an underestimation with respect to the actual physical distance. This may be seen by looking at the bracketed numbers in Table 1 (Columns 3 and 4), in which the mean distance estimates for each observation condition are expressed as the mean ratio of the perceived to the objective distance. These ratios were obtained by establishing an individual ratio of perceived to actual distance for each $\mathbf{S}$ and then calculating the mean. All mean tracking distance estimates represent an actual underestimation of the distance traversed by the target. The overall mean underestimation based on all Ss who made tracking distance estimates is $13 \%$. This may be compared with the overall mean ratio of all nontracking distance estimates, which represents a . $1 \%$ underestimation of distance.
Because velocity is, at least mathematically and logically, inextricably related to frontal-parallel distance, it seemed reasonable to ask whether the underestimation of tracked distance was related to the Aubert-Fleischl phenomenon, the underestimation of the velocity of a tracked and moving target. To answer this question, velocity estimates following tracking of a standard moving target were compared with the estimates obtained following the observation of the moving standard while fixating a stationary point located in the midpoint of the target track. (These are the essential conditions for obtaining the Aubert-Fleischl effect.)

\section{EXPERIMENT III Apparatus}

The apparatus consisted of a standard $1 / 2$-in. luminous target disk, mechanically driven at a speed of either 4.5 or $10.5 \mathrm{deg} / \mathrm{sec}$ through an angle of $90 \mathrm{deg}, 3$ and a comparison target, driven in the same way but the speed of which could be varied between 0 and $20 \mathrm{deg} / \mathrm{sec}$. Black cardboard masks were placed at both ends of the target tracks so that the target appeared and then disappeared from view behind them. One-millimeter fixation points were located in the centers of the target tracks in the S's median plane. The standard target traveled along a horizontal path, $30 \mathrm{~cm}$ from the $S$ and slightly above his eye level. The comparison target, which was the same distance away, traveled on a path slightly below eye level. A white matte board placed behind the target tracks was the only visible background when the room lights were on.
Procedure

In the tracking condition, the Ss were instructed to follow the moving target with their eyes when it appeared until it disappeared from view. In the fixation condition, Ss were told to fixate the stationary luminous point while they observed the moving target. In both conditions, the lab room was completely dark. Immediately following standard target observation, the room lights were turned on and the $\mathbf{S}$ fixated the stationary point in the center of the comparison target tracks. The $E$ increased or decreased the comparison target speed until the $S$ was satisfied that its speed matched that of the standard. There were 10 tracking and 10 fixation trials, each preceded by two practice trials.

\section{Subjects}

Twelve Ss were tested, six with a standard target velocity of $4.5 \mathrm{deg} / \mathrm{sec}$ and six with a velocity of $10.5 \mathrm{deg} / \mathrm{sec}$. The six $S s$ in the $10.5 \mathrm{deg} / \mathrm{sec}$ condition were the same Ss who served in the $10.5 \mathrm{deg} / \mathrm{sec}$ distance estimate experiment, and the six $S$ s in the $4.5 \mathrm{deg} / \mathrm{sec}$ condition had also served in the $4.5 \mathrm{deg} / \mathrm{sec}$ distance condition.

\section{Results}

The mean differences between tracking and fixation in the $4.5 \mathrm{deg} / \mathrm{sec}$ and the $10.5 \mathrm{deg} / \mathrm{sec}$ are reported in Lines 5 and 6 of Table 1. These differences are significant. It should, however, be pointed out that the difference between the differences of the 10.5 and $4.5 \mathrm{deg} / \mathrm{sec}$ conditions is not significant, and thus the magnitude of the underestimation of velocity during tracking at the speeds tested appears to be approximately $1 \mathrm{deg} / \mathrm{sec}$.

\section{iscussion}

If the underestimation of distance is, in fact, related to the underestimation of velocity, then certain predictions follow from the velocity estimation data. Predictions: (1) Since the magnitude of the underestimation of velocity is about the same for tracked targets moving at 4.5 and at $10.5 \mathrm{deg} / \mathrm{sec}$, we would expect a greater underestimation of distance if the target is tracked at $4.5 \mathrm{deg} / \mathrm{sec}$ than at $10.5 \mathrm{deg} / \mathrm{sec}$, provided that the actual distance traveled was the same. This prediction is confirmed by the data. The $4.5 \mathrm{deg} / \mathrm{sec}$ condition yielded a greater underestimation of distance than the $10.5 \mathrm{deg} / \mathrm{sec}$ condition $\left(t_{1}=4.5 \alpha .01\right)$ (see Lines 1 and 2 of Table 1 ) (2) Since the magnitude of the underestimation of velocity is fairly constant at the two tracking speeds, equivalent underestimations of distance should be obtained when the 
the tracking time is equated. This prediction was confirmed by Experiment IV.

\section{EXPERIMENT IV}

Ss estimated the distance traveled by a tracked target moving at $10.5 \mathrm{deg} / \mathrm{sec}$, through an angle of $46.67 \mathrm{deg}(26.6 \mathrm{~cm})$. The time required for the tracked target to complete its excursion was $4.4 \mathrm{sec}$, the same time it took the target moving at $4.5 \mathrm{deg} / \mathrm{sec}$ to traverse $20 \mathrm{deg}$ (the condition of Experiment I). These distance estimates were compared with those made following saccadic observation of two successively appearing lights separated by the same distance.

\section{Apparatus}

The apparatus used in Experiment I was modified in the following ways. The moving target now traveled from a point $23.3 \mathrm{deg}$ left of the S's median plane to a point $23.3 \mathrm{deg}$ to the right of it, at which point it disappeared from view. The lights demarking the fixation positions used in the saccadic condition were separated by an angle of $46.67 \mathrm{deg}$. The initial light remained in the S's median plane. The second light was relocated $46.67 \mathrm{deg}$ to its right.

The procedure was identical to that of Experiment I. Six Ss were tested.

\section{Results}

Line 4 of Table 1 reports this data. The mean difference between distance estimates in the saccadic and tracking condition was $2.89 \mathrm{~cm}$, which is not significantly different from the difference obtained in the $4.5 \mathrm{deg} / \mathrm{sec}$ condition of Experiment $1\left(t_{1},=.18\right)$, thus confirming the second prediction.

One final prediction may be derived from the hypothesis that the underestimation of tracking speed and tracking distance are related. Namely: (3) Given an underestimation of velocity of about $1 \mathrm{deg} / \mathrm{sec}$ and a direct relationship between velocity and distance perception during tracking, we would expect an underestimation of distance in the $4.5 \mathrm{deg} / \mathrm{sec}$ condition in which the target traveled $20 \mathrm{deg}$ and the $10.5 \mathrm{deg} / \mathrm{sec}$ of this last experiment of about $4.5 \mathrm{deg}$. The obtained underestimations are equivalent to 4.4 and $5.5 \mathrm{deg}$, respectively. We would predict an underestimation of about $2 \mathrm{deg}$ in the $10.5 \mathrm{deg} / \mathrm{sec}$ condition in which the target traveled $20 \mathrm{deg}$. The obtained mean underestimation was equivalent to $2.3 \mathrm{deg}$. The obtained underestimations are sufficiently close to the predicted figures to suggest, along with the other data, that a relationship exists between velocity and frontal parallel distance perception during tracking.

It is perhaps worth noting that two salient characteristics of an apparently now forgotten illusion, also dependent on pursuit tracking, provide another instance of a linked underestimation of distance traversed and rate of movement of a tracked target. This illusion, first described by Dodge (1904) and labeled by Carr (1907), is the pendular whiplash illusion and is obtained when one of two moving lights attached at equal distances from the center of rotation to the two arms of a counterbalanced pendulum is pursuit tracked. The illusion is such that when the tracked light approaches the extreme position in each oscillation, it seems to rest, while the nonfixated point appears to continue moving for an appreciable interval. Ford (1910), in a report of an investigation of this illusion, states that Ss consistently report that the tracked light is seen to move through a shorter distance and at a slower speed than the nonfixated light.

A major puzzle growing out of our findings is how to account for the misperceptions of both distance and velocity. One possibility might be the following. Other data (Mack \& Herman, in press) suggest that the underestimation of velocity during tracking may be the result of an underregistration of the rate of pursuit eye movements. Were this the case, the underestimation of distance might follow. If we assume that the principal source of information about eye movements is efferent information (Brindley \& Merton, 1960) and if we assume further that the registered efferent information derived from pursuit eye movements concerns the rate of the eye movement rather than eye position, then under conditions in which a single visible and moving target is accurately tracked, the only source of information concerning the distance traversed by both the eye and target must come from the registered efferent-rate information. No other information would seem to be available. If this reasoning is valid, and there is a consistent underestimation of pursuit eye movement rate, then there must also be a predictable misperception and an underestimation of the distance traveled by a pursuit-tracked target. But, be this as it may, the data reported here establish that there is a consistent underestimation of tracking speed.
These facts, while clearly significant for the study of visual perception, must await a more firmly grounded theoretical explanation.

\section{REFERENCES}

BR INDLEY, G S \& MERTON, P. A. The absence of position sense in the human eye. Journal of Physiology, 1960, 153, 127-130.

DODGE, $R$. The participation of eye movements in the visual perception of motion. Psychological Review, 1904, 11 , 1-14.

CARR, H. The pendular whiplash illusion, Psychological Review, 1907, 14, 169-182. FESTINGER, L., \& CANON, L. K. Information about spatial location based on knowledge about efference. on knowledge about efference.
Psychological Review, 1965, 72, 373-384. FILHENE, W. Über das optische Wahrnehmen von Bewegungen. Zeitschrift für Sinnesphysiologie, 1922, $53,134-145$.

FLEISCHL, E. Physiologisch-optische Notizen. Sitzungsberichte der Akademie der Wissenschaften, 1882, 86, 17-25.

FORD, A. The pendular whiplash illusion. Psychological Review, 1907, 17, 192-204.

MACK, A., \& HERMAN, E. Position constancy during pursuit eye movement: An investigation of the Filhene illusion. Psychology, in press.

\section{NOTES}

1. The rationale for initiating saccadic observation with fixation in the S's median plane and tracking observation with fixation $10 \mathrm{deg}$ to the left of that plane rather than initiating both conditions with the same direction of gaze was that this lessened the likelihood that the $S$ would attempt to make consistent judgments across the two conditions because he knew that the distance demarked by the saccadic lights and the traveling target was identical. He might certainly have known this if the saccadic lights had been located in the same egocentric positions as the beginning and end point of the moving target.

2 . In order to establish that any differences obtained were not merely a function of the fact that the target always displaced to the right, six Ss were tested under conditions in which the target displaced either to the right or to the left. Thus, its movement on any given trial was never predictable. The experimental conditions were identical in every other way to those already described. The tracking target at the onset of each trial was located 10 deg to the left of the S's median plane and moved either $20 \mathrm{deg}$ to the right or left at $4.5 \mathrm{deg} / \mathrm{sec}$. In the saccadic condition, the initial light came on in the median plane and the second light came on either 20 deg to the right or left. The mean estimate of tracking distance $w a s 10.10 \mathrm{~cm}$ and is to be compared with a mean saccadic distance estimate of $11.62 \mathrm{~cm}$. This difference of $1.62 \mathrm{~cm}$ again represents a clear underestimation of tracking distance, $t_{5}=4.68 \alpha .01$

3. A 90-deg observation angle was used rather than the 20-deg angle of Experiment I, because pilot testing had indicated that the 20-deg angle did not allow adequate time for the $S$ to arrive at an estimate of speed with which he was at all setisfied.

(Received fo;publication February 7, 1972; revision received May 25, 1972.) 